Annales Geophysicae (2002) 20: 237-245 (c) European Geophysical Society 2002

\title{
Synoptic conditions leading to extremely high temperatures in Madrid
}

\author{
R. García ${ }^{1}$, L. Prieto ${ }^{1}$, J. Díaz ${ }^{2}$, E. Hernández ${ }^{1}$, and T. del Teso ${ }^{1}$ \\ ${ }^{1}$ Depto. Física de la Tierra II; Fac. CC. Físicas; Univ. Camplutense de Madrid, Spain \\ ${ }^{2}$ Centro Universitario de Salud Pública, Universidad Autónoma de Madrid, Spain
}

Received: 12 March 2001 - Revised: 19 September 2001 - Accepted: 20 September 2001

\begin{abstract}
Extremely hot days (EHD) in Madrid have been analysed to determine the synoptic patterns that produce EHDs during the period of 1955-1998. An EHD is defined as a day with maximum temperature higher than $36.5^{\circ} \mathrm{C}$, a value which is the threshold for the intense effects on mortatility and it coincides with the 95 percentile of the series. Two different situations have been detected as being responsible for an EHD occurrence, one more dynamical, produced by southern fluxes, and another associated with a stagnation situation over Iberia of a longer duration. Both account for $92 \%$ of the total number of days, thus providing an efficient classification framework. A circulation index has been derived to characterise and forecast an EHD occurrence. This paper shows that EHD occur in Madrid during short duration events, and no long heat waves, like those recorded in other cities, are present. Additionally, no clear pattern can be detected in the EHD frequency; the occurrence is tied to changes in the summer location of the Azores high.
\end{abstract}

Key words. Meteorology and atmospheric dynamics (Climatology; synoptic-scale meteorology; general or miscellaneous)

\section{Introduction}

The interest in the study of extremely hot temperature events has increased in the last few years due to a number of factors. There is wide evidence that temperature extreme values show significant trends, either positive or negative, in different regions of the planet (Karl, 1996; Plummer, 1999; Easterling, 2000). Those changes detected in the actual observed extreme temperatures seem likely to continue in the future (IPCC, 1995; Ungar, 1999). Although there is no general agreement, most of the models forecast scenarios where more hot summer days and higher maximum temperatures are very likely to occur (Easterling, 2000). The most relevant direct impact of these extremely hot events is the in-

Correspondence to: L. Prieto (luis@ 6000aire.fis.ucm.es) crease in mortality, primarily associated with cardiovascular diseases among the elderly (Pan, 1995; Woodhouse, 1994). Kalkstein and Greene (1997) consider that "heat waves" are the most important cause of death due to natural hazards. In fact, they seem to be one of the few meteorological hazards whose associated mortality is increasing during the last few years (Changnon et al., 1996).

Most of these studies consider the association between mortality and heat through the use of different types of statistical models to identify the effects that are really associated with hot temperature and to evaluate those effects due to different air pollutants. There have been attempts to include variables associated with atmospheric circulation (González et al., 2001). In some cases (Kalkstein, 1991; Kalkstein et al., 1996) a different approach is used by considering the weather types that cause these extreme values through the use of objective schemes.

In Madrid, the association between temperature and mortality shows an V-shape, similar to that found in different cities (Alberdi et al., 1998; Sáez et al., 1995; Kunst et al., 1993), with minimum mortality for a daily maximum temperature of $30.8^{\circ} \mathrm{C}$. However, Madrid shows a summer increase in mortality which is higher than that evidenced in other areas with intense thermal extremes (Greenberg et al., 1983; Lye and Kamal, 1997; Macey and Schneider, 1993). Figure 1 shows the association between mortality (organiccause in women over 75) and daily maximum temperature for the period. It is evident that a sharp increase occurs in the slope of the adjusted regression line for temperatures above $36.5^{\circ} \mathrm{C}$. Therefore, this value can be considered as a threshold for the occurrence of "heat waves" or high mortality episodes. This is a value similar to those found for Japan (Nakai, 1999) or Chicago (Whitman et al., 1997), but lower than those found for St. Louis (Smoyer, 1998). It is interesting to note that humidity does not seem to play a relevant role in this type of episode in Madrid (Alberdi et al., 1998; Díaz et al., 1999; González et al., 2001). A complete description of the association between extreme temperature and mortality can be found in Díaz et al. (2001). 


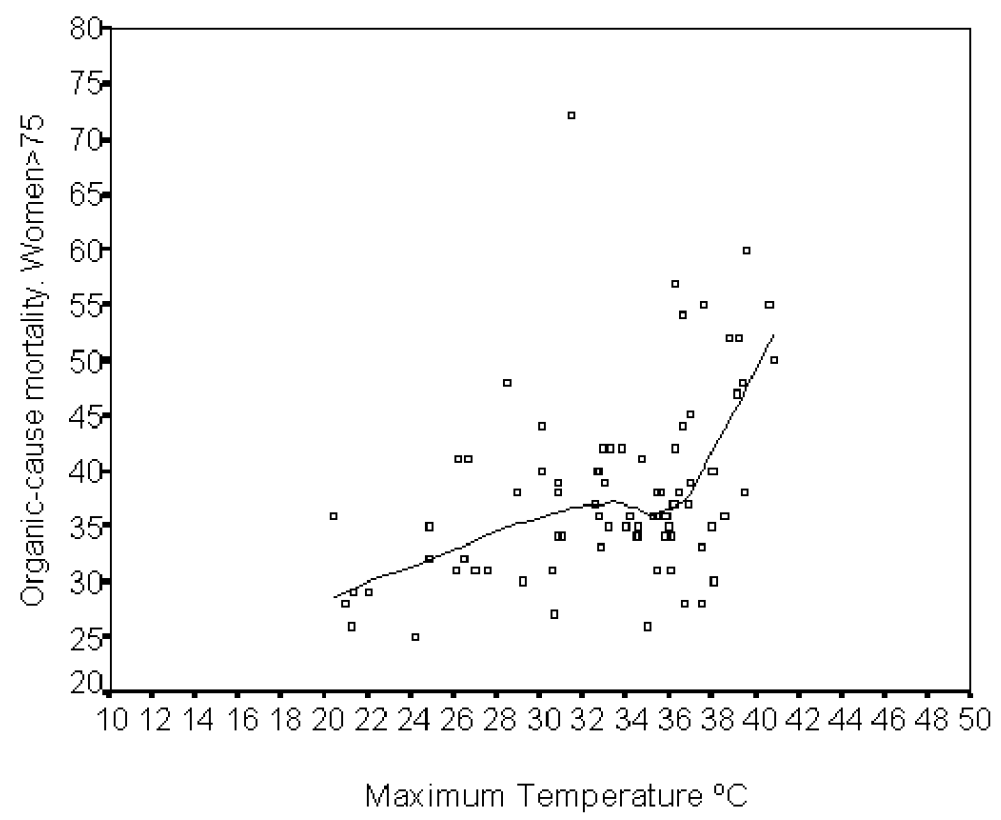

Fig. 1. Association between daily mortality (number of deaths) among women over 75 , due to a organic causes and the daily maximum temperature in Madrid $\left({ }^{\circ} \mathrm{C}\right)$.
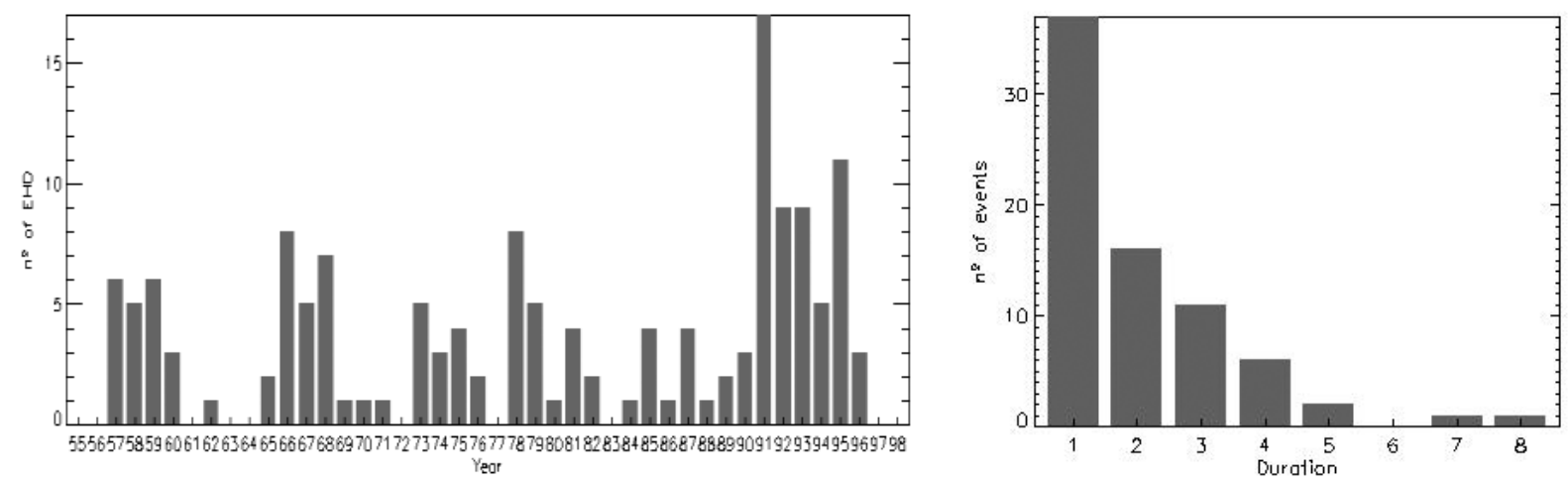

Fig. 2. (a) Annual EHD frequency in Madrid during the period of 1955-1998. Frequency is expressed as the number of days with a maximum temperature above $36.5^{\circ} \mathrm{C}$ per year. (b) Histogram of the duration of EHD periods.

The main objective of this paper is to identify the synoptic patterns leading to extreme temperature values in Madrid; among similar previous studies, those by Karl and Quayle (1981) and Chang and Wallace (1987) can be cited. The paper is organized as follows: Sect. 2 provides a statistical analysis of the occurrence of extremely hot days (EHD), Sects. 3 and 4 describe the synoptic patterns leading to the occurrence of very hot days. The final remarks are included in Sect. 5.

\section{Occurrence of very hot days}

Maximum daily temperature in the summer months (June, July, August and September) have been analysed to characterize heat wave occurrence in Madrid. According to the previous section, those days with temperatures above $36.5^{\circ} \mathrm{C}$ have been considered as very hot days. The study covers the period of 1955-1998. The daily temperature series has been taken from the Spanish Meteorological Service (INM), in the observatory of Madrid-Retiro. Data used in the synoptic analysis and other calculations have been taken from NCEP/NCAR reanalysis (Kalnay et al., 1996), available for the whole study period on a $2.5^{\circ} \times 2.5^{\circ}$ grid.

Figure 2 shows the number of heat days per year (panel (a) and the histogram of the duration of the heat day runs (i.e. number of consecutive days exceeding the threshold value; panel (b). Panel (a) shows that the occurrence of temperature in excess of the threshold value is a very rare phenomenon in Madrid; in fact, it is also the 95 percentile of the daily temperature series. Great interannual variability is also evident, with 10 years (22\%) without a day containing values above the threshold. The 1990s shows a higher incidence of very hot days, but the difference with the rest is 

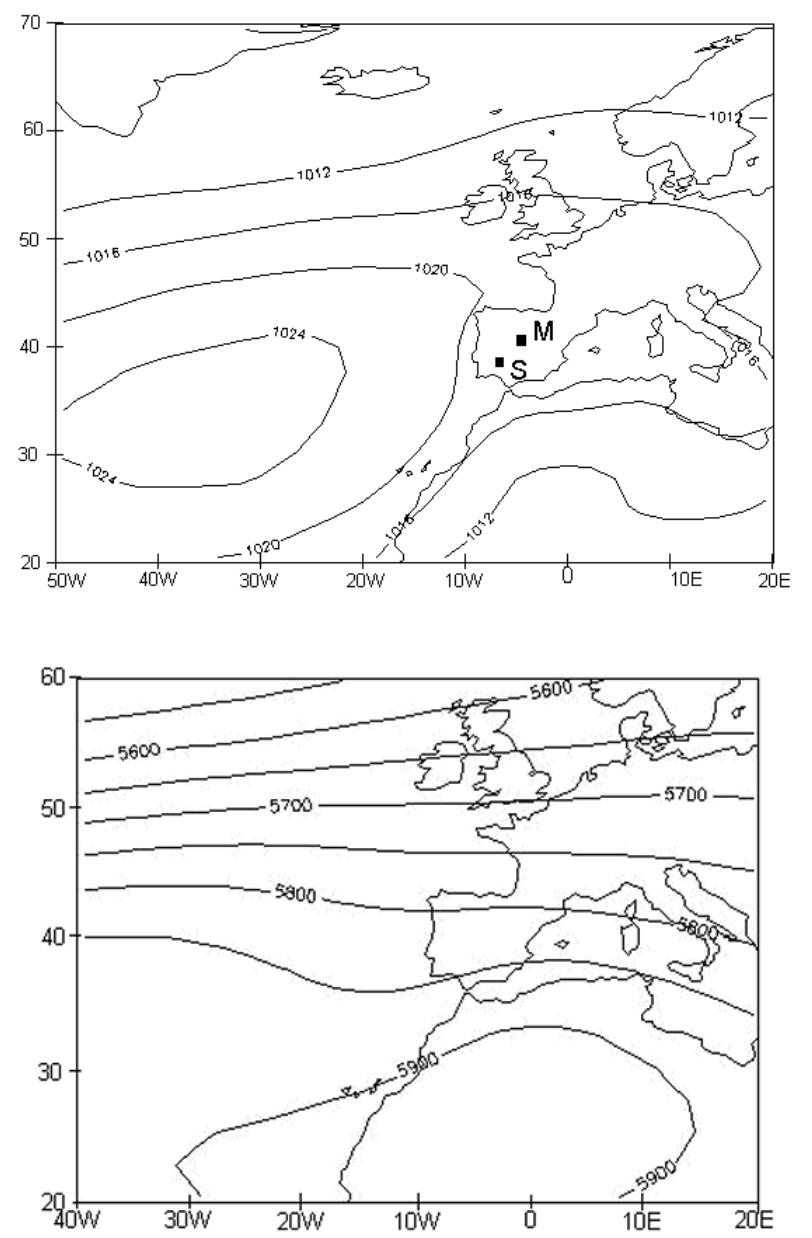

Fig. 3. (a) SLP average for June to September during the 19551998 period. $\mathrm{M}$ and $\mathrm{S}$ indicate the respective location of Madrid and Seville. (b) Similar to (a), but for $Z_{500}$.

not statistically significant when a student t-test is applied. After investigating the relationship between the seasonal frequency and the variables, such as average summer temperature, average annual temperature and the different circulation indices relevant for the atmospheric circulation over the Iberian Peninsula, no significant driving variable could be detected, nor could any regular time pattern be identified. However, it can be seen that there is a nonlinear association between the monthly average maximum temperature and the monthly EHD frequency. Months with average maximum temperature higher than $32.1^{\circ} \mathrm{C}$ (which correspond to the expected value plus the standard deviation for the daily maximum temperature) show an average EHD frequency of 2.82 $( \pm 2.43)$ days/month (sigma values between brackets), while the rest show an average EHD frequency of $0.36( \pm 0.84)$ days/month. The difference is significant $(p<0.01)$ after a two-tailed student t-test.

From panel (b), it is evident that for most of the time (50\% of the cases), the occurrence of temperatures in excess of the threshold occurs in isolation, with one single day above $36.5^{\circ} \mathrm{C}$. Additionally, the duration of the periods only ex-
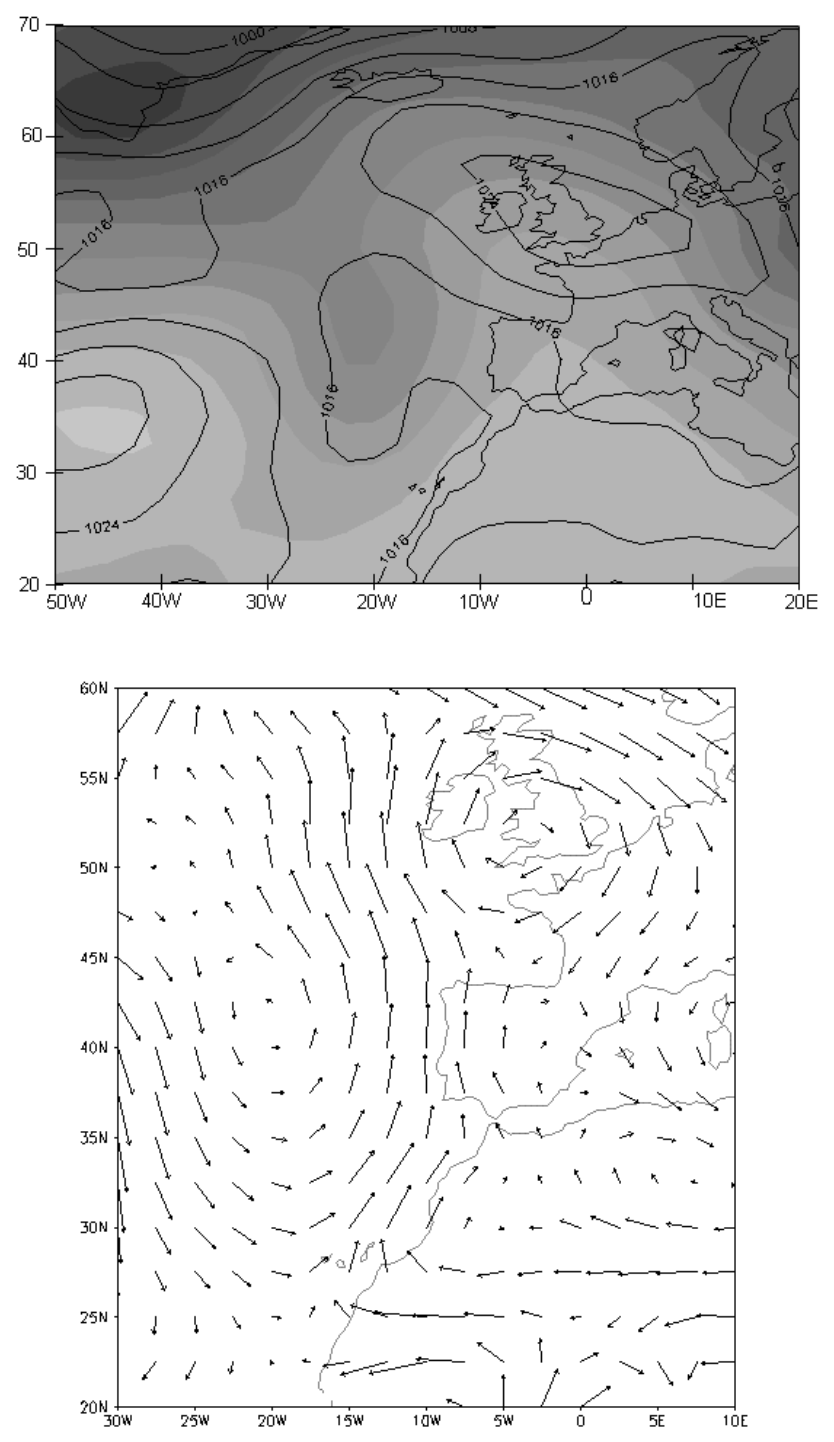

Fig. 4. (a) SLP and $Z_{500}$ field for 19 July 1989, corresponding to a selected southern flux situation. (b) Similar to (a), but for the wind at $850 \mathrm{hPa}$.

ceeds 5 days in two cases. This lack of persistence in the extreme hot days is rather characteristic of Madrid, where no long, extreme hot periods have occurred during the study period. The maximum length (8 days) is similar to that recorded in Athens during 1987 (Katsouyanni et al., 1993). On the contrary, there are abundant references in the literature on the occurrence of prolonged heat waves in different cities (Smoyer, 1998; Smoyer et al., 2000; Greenberg et al., 1983), with a maximum length for that recorded in Belgium in 1994 (42 days, above $27.5^{\circ} \mathrm{C}$; Sartor et al., 1995). However, one must be cautious when making a comparison to other studies, since there does not exist a homogeneous way to define an EHD, as can be seen in the cited references, where the threshold is fixed depending on the value of the effect produced by the apparent temperature (Smoyer, 1998; Smoyer et al., 2000), which represents the occurrence of a certain impact on a case-control study (Sartor et al., 1995). 


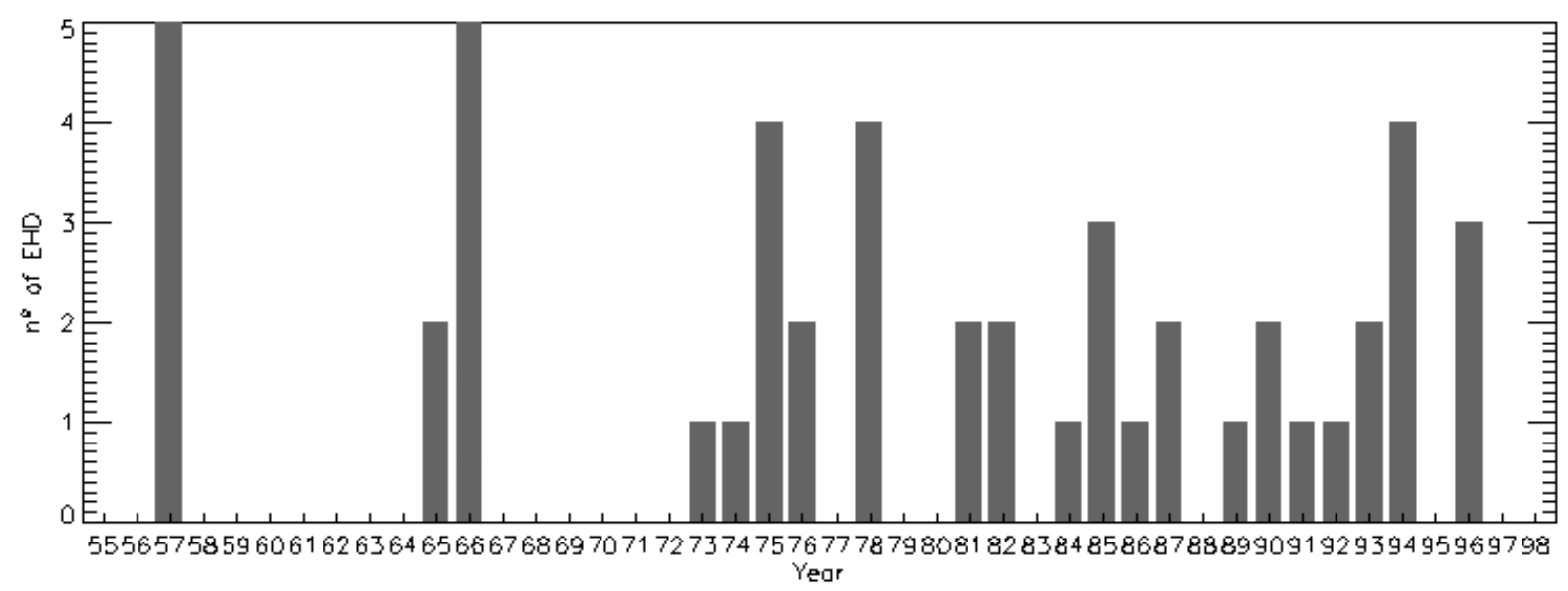

Fig. 5. Annual frequency for EHD occurring under southern flux conditions.

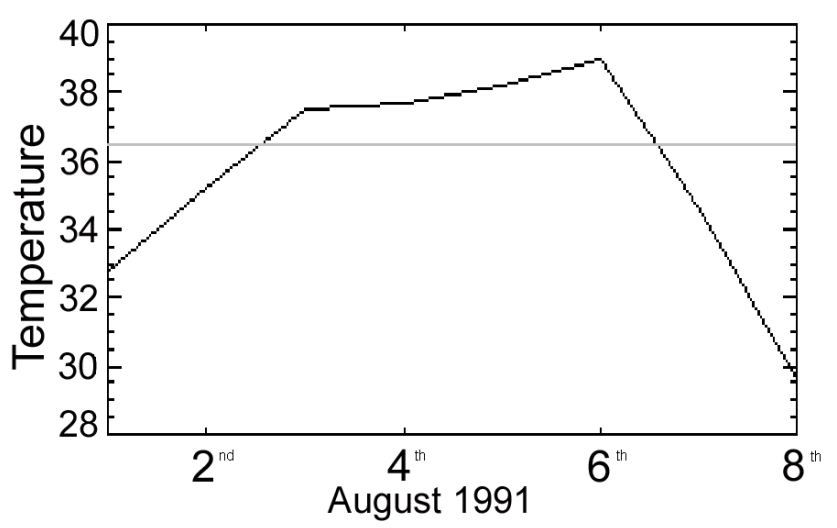

Fig. 6. Evolution of maximum daily temperature during the stagnation period that occurred between 3 and 6 August 1991.

A first approach for the analysis of these extreme values was the use of techniques, such as Rotated Principal Component Analysis (Richman, 1986) or Canonical Correlation Analysis (CCA, von Stoch and Zwiers, 1999) to identify and characterize the synoptic conditions associated with their occurrence. The identification of synoptic patterns through the use of air-mass analysis was also attempted (Kalkstein, 1996). None of the previous attempts yielded efficient results. So, an alternative approach was used based on a case-by-case analysis. First, the days with a maximum temperature above $36.5^{\circ} \mathrm{C}$ were selected. Next, their sea level pressure (SLP), the $500 \mathrm{hPa}$ geopotential height, the $850 \mathrm{hPa}$ analyzed wind, and the surface temperature from the NCEP reanalysis were analysed through a subjective procedure, taking into account the respective anomaly fields. Figure 3 shows SLP and the $500 \mathrm{hPa}$ geopotential height averages during the summer months for the considered period. It can be seen that the subtropical Azores' high blocks the surface circulation over Iberia, while there is a zonal pattern at $500 \mathrm{hPa}$, with Iberia in its southern edge. Thus, small changes in the location of this zonal belt can lead to high variations in the circulation over the Iberian Peninsula. After careful examination of the 151 days when the recorded maximum temperature was higher than $36.5^{\circ} \mathrm{C}$, two synoptic patterns could be identified: the southern flux situation and the stagnation situation. In the following sections, a detailed description is provided for both situations.

\section{Southern flux situation}

This type of situation usually occurs due to the joint effect of a trough, located between $15^{\circ}$ and $40^{\circ} \mathrm{W}$, with its axis directed north to south, and a small ridge, with its center over Iberia. Figure 4 shows a typical example of such situations (it corresponds to 19 July 1989, with a maximum temperature of $37.2^{\circ} \mathrm{C}$ ). Apparently, such a configuration should produce fresh and moist southwestern winds over the Portuguese coast. However, the analyzed winds at $850 \mathrm{hPa}$ show that the prevailing flow injects hot and dry air from North Africa onto Iberia. An anticyclonic circulation favours this transport over North Africa that intensifies the flux over eastern Spain. The effect of the trough is the generation of a meridian flow, which results in the transport of hot air from the south. Usually, the deeper the trough is, the hotter the air, since it comes from the more southern regions. In fact, during summer, North Africa lies in the subtropical subsidence region. Therefore, very high solar irradiance and very low latent heat fluxes lead to extreme temperatures above $40^{\circ} \mathrm{S}$. Similar conditions are recorded in southern Iberia due to the presence of the ridge.

It can be noted in panel (a), which shows the $500 \mathrm{hPa}$ geopotential height, that the trough is not especially deep $(5720 \mathrm{~m})$, but it is enough to induce southern flows into central Iberia. Panel (b) shows the wind pattern with values above $8 \mathrm{~m} / \mathrm{s}$. The occurrence of these situations concentrates during the period between 15 June and 1 September, with maximum incidence for July. Figure 5 shows the annual frequency of such days (expressed as days per year). It can be seen that it is very low, with a maximum of 5 days/year for 
1957 and 1966 . Only 21 years from the total period show at least one day with this type of situation. It must be noted that these situations are very rare before 1973 (occurring in only three years: 1957, 1965 and 1966). After 1973, the occurrence seems more regular, but without any typical distribution structure.

Since the pattern is characterized by significant flows produced by the arrival of the trough, it usually evolves rapidly, producing a westerly wind from the Atlantic sector after 24 or $48 \mathrm{~h}$. This causes the temperature increase to be limited to a maximum of 2 days, and occurring primarily in isolated days with few persistence. In fact, there are 49 EHD that originate from this pattern: 30 of them are isolated, and in only in 19 cases (39\%), they are present for a period longer than two consecutive days. However, it must be emphasized that the maximum recorded temperatures have originated when the pattern extended its duration up to 5 days (as was the case in July-August 1957; August 1966 and July 1978 with maximum temperatures above $39^{\circ} \mathrm{C}$ ). In all three cases, the pattern showed a more stationary behaviour than usual, with a deeper and larger ridge. This produced a longer persistence, thus the southern, hotter and dryer air reached Iberia.

\section{Stagnation situations}

Stagnation configurations are rather different from those that originate from southern fluxes. They occur when the subtropical high at $500 \mathrm{hPa}$ moves northward onto Iberia. This displacement produces stagnation in the middle troposphere, which extends downward to the surface when the permanent Azores' high is displaced northeast from its usual location over western Europe. The combination of both factors, at the surface and at $500 \mathrm{hPa}$, usually leads to a calm or very weak northward wind due to the effect of the development of a thermic low over southern Iberian and northern Morocco. These episodes usually last between 1 to 5 days, when the temperature rises abruptly, causing extreme values. The breakdown of this situation is primarily due to the southward displacement of the westerlies; thus, Atlantic air is injected over the area. This can be intensified by two factors, which usually occur jointly and break the surface situation. The first and the most important is the intensification of the high over the Azores Islands, which induces a northward surface wind over Iberia. The other factor is the development of a thermic low over southern Iberia with the reinforcements of the northern flow. Figures 6,7 and 8 show a typical example of a stagnation episode from 3 August 1991 to 6 August 1991. Figure 6 shows the maximum temperature evolution. Figure 7 represents SLP and $500 \mathrm{hPa}$ geopotential height fields at 12:00 UT for 3, 5 and 7 August 1991. Figure 8 shows the $850 \mathrm{hPa}$ corresponding wind fields. It can be observed that the event starts when the surface Azores' high and the highlevel subtropical high extends onto Iberia, with calm or very low winds. As days pass, a thermic low develops over the Alboran Sea. The low finally breaks the surface high and the
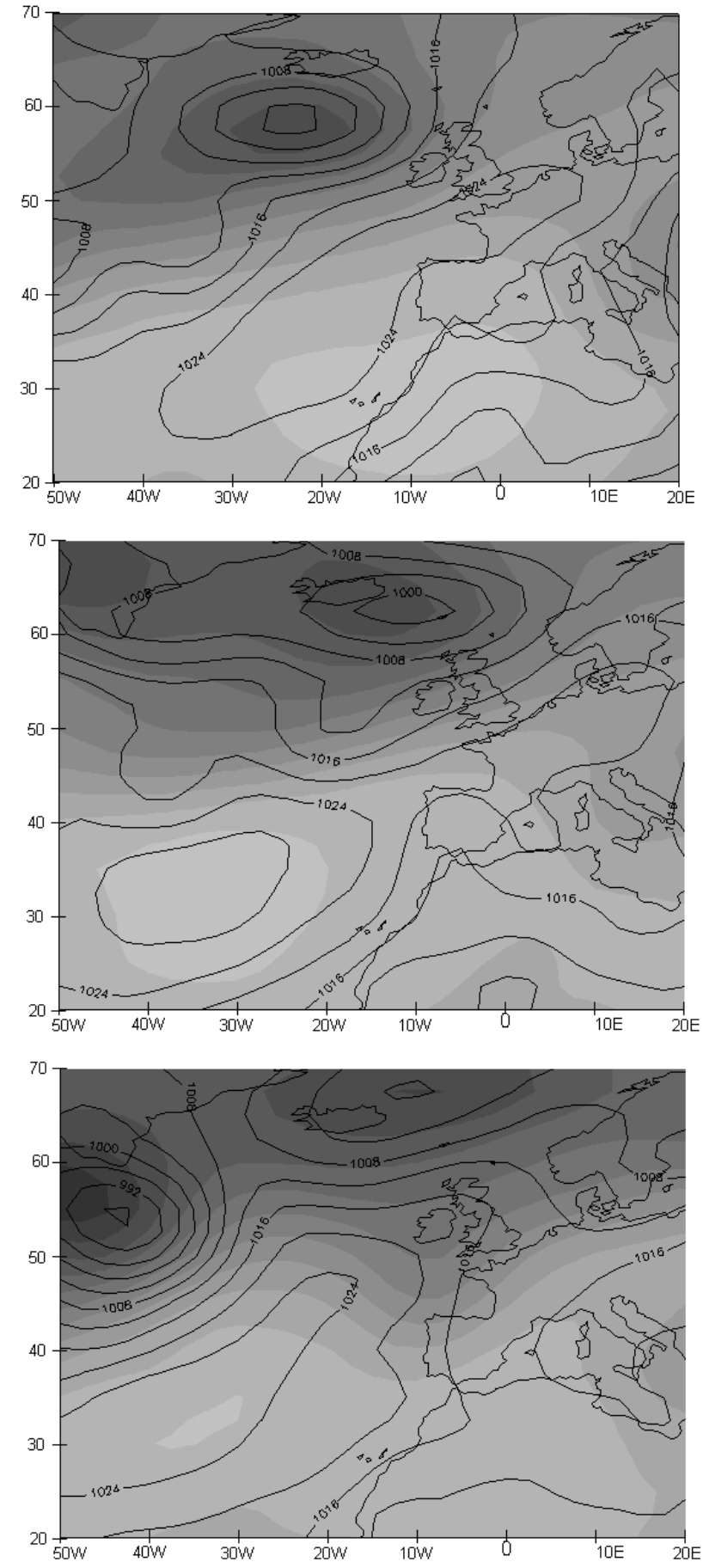

Fig. 7. SLP and $Z_{500}$ field for 3, 5 and 7 August.

configuration evolves to a trough, which injects Atlantic air over the peninsula. In the corresponding temperature field (not shown here), it can be noted how the high temperature field extends northward as the situation evolves and the arrival of fresh Atlantic air over the west occurs after day 6.

A total of 90 days were detected. It must be noted that 63 of them $(70 \%)$ were recorded within events with a duration longer than two days. Figure 9 shows the annual frequency 

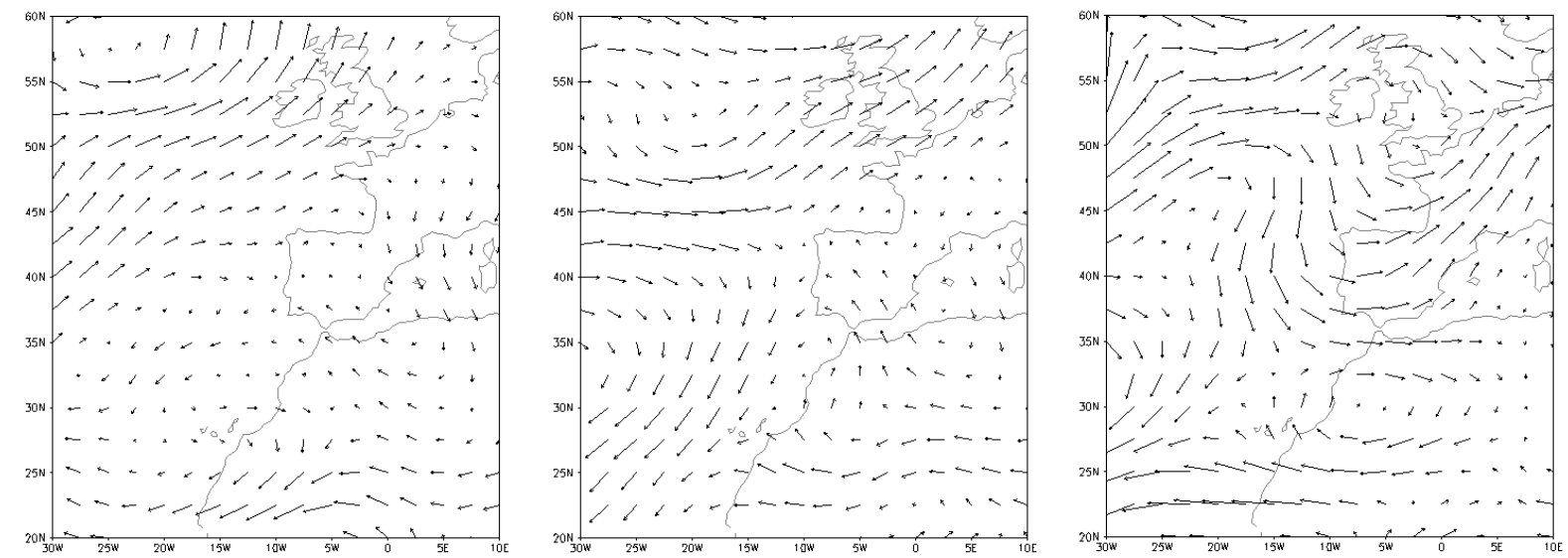

Fig. 8. Similar to Fig. 7, but for the analyzed wind at $850 \mathrm{hPa}$.

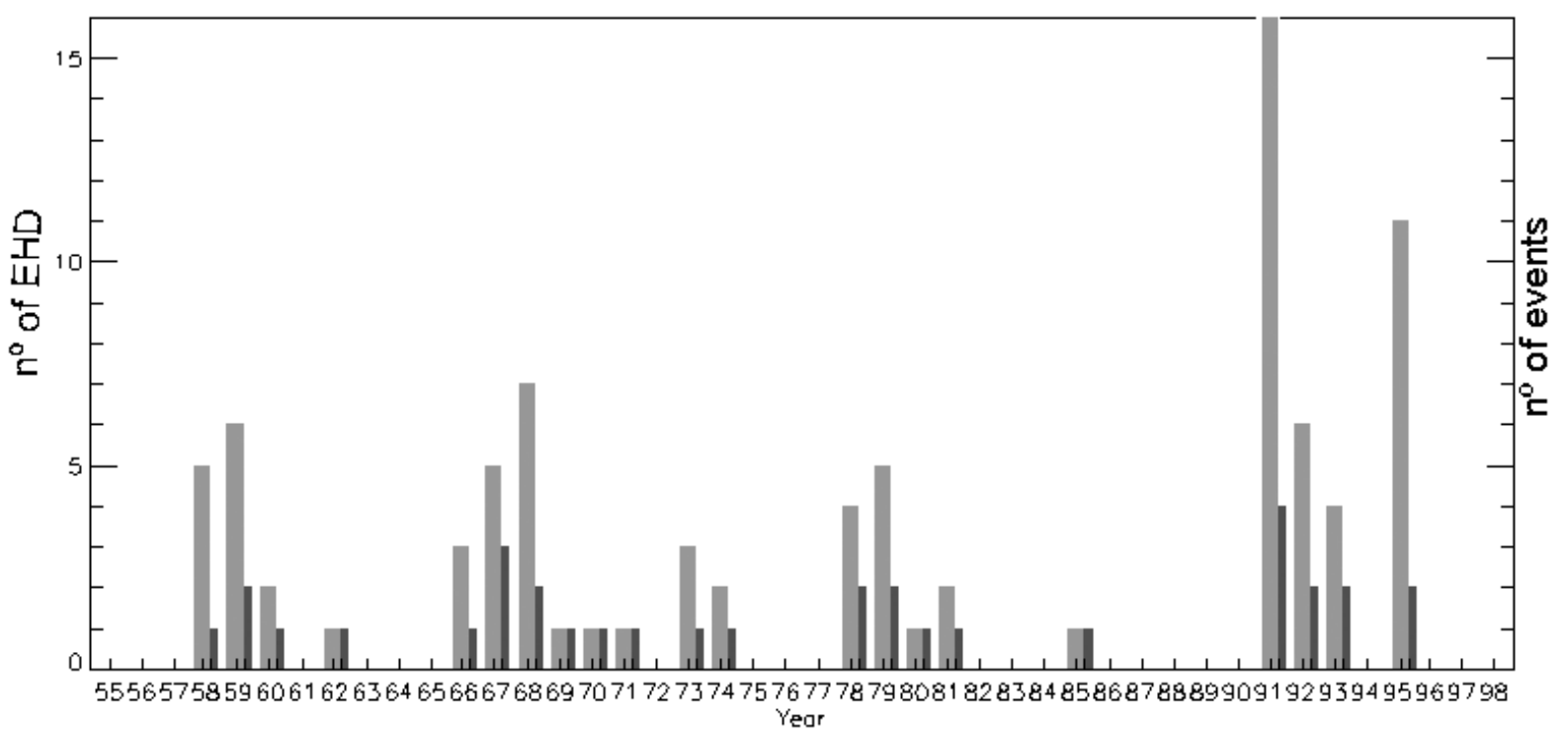

Fig. 9. Annual frequency of EHD (grey) and EH events (black) for the 1955-1998 study period.

of these situations during the study period. It can be seen that there are 19 years with no occurrence of a stagnation situation, while 9 years show more than one stagnation event. No clear trend is evident on the distribution, with the highest occurrence of EHD during the 1991-1995 period, with 4 events in 1991 (16 days total duration) and two events in 1992, 1993 and 1995. No apparent relationship between the total number of EHD and the average summer temperatures during the considered period has been detected.

To assess the possibility of any changes that may span several decades, the study period was divided into 4, eleven year periods: 1955-65, 1966-76, 1977-87 and 1988-98. Figure 10 shows the decadal $500 \mathrm{hPa}$ geopotential heights for those days that belong to a heat wave event due to a stagnation situation. In all of them, a ridge configuration is evident but that is more intense at the end of the study period. This increase in the intensity is better depicted by the shadowed areas, which show geopotential anomalies higher than one standard deviation. It is evident that the extent of the area increases as the decades pass, coinciding with a higher number of events, which, in addition, last longer during the last decade.

The presence of the $500 \mathrm{hPa}$ high displacement seems to be a key point for the detection of this kind of pattern. This observation has allowed one to develop a circulation index (CI) that adequately characterizes the occurrence of stagnation episodes. For this purpose, the grid, delimited by $35.0^{\circ} \mathrm{N}$ and $50.0^{\circ} \mathrm{N}$ in latitude and $17.5^{\circ} \mathrm{W}$ and $5.0^{\circ} \mathrm{E}$ in longitude, was considered (location shown in Fig. 9a, with a $2.5^{\circ}$ resolution. The difference between the actual geopotential height and the reference value of $5920 \mathrm{~m}$ is then computed for every gridpoint and then averaged. Thus, this mean anomaly can be expressed by:

$\mathrm{CI}=\overline{\left(5920-z_{i j}\right)}$ 

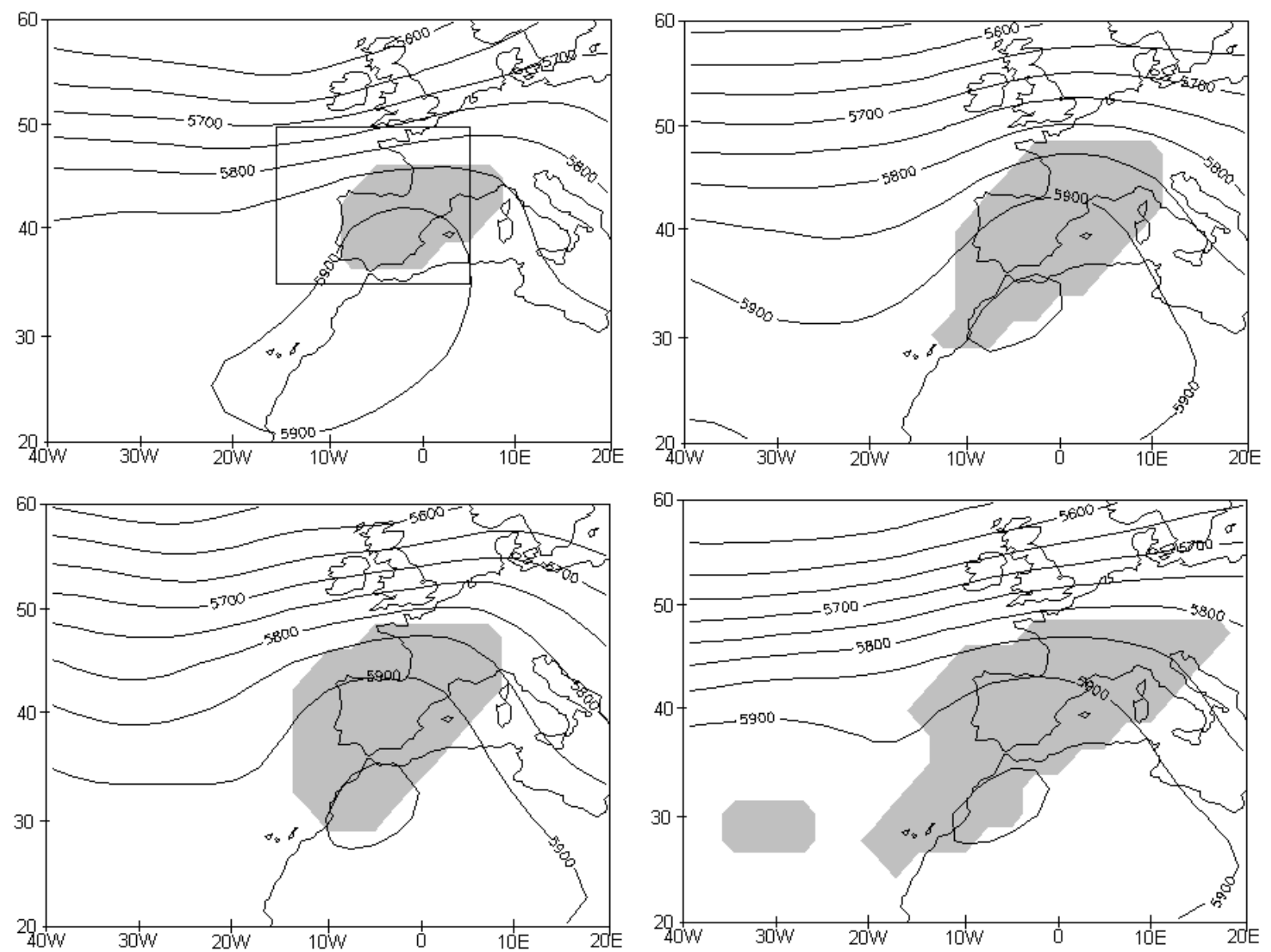

Fig. 10. (a) $Z_{500}$ composites (June to September) for the period of 1955-1965. Shadowed area represents values with anomalies higher than one standard deviation. The square shows the area used to compute CI (see text for details). (b) (a), but for the period of 1966-1976. (c) (a), but for the period of 1977-1987. (d) (a), but for the period of 1988-1998.

where $i j$ represent the grid points. The $5920 \mathrm{~m}$ reference value has been chosen after different trials in order to optimize its representativeness of the circulation (and consequently, stagnation occurrence) over central Iberia. Thus, high CI values are associated with the presence of a trough over Iberia and, therefore, low temperatures, while low CI values should correspond to stagnation, i.e. high temperatures. The effect of low CI values (stagnetion episodes) is the increase in temperature; this leads to an EHD when the initial maximum temperature is above $26^{\circ} \mathrm{C}$. If this threshold is not exceeded, then high (low) $\mathrm{CI}$ values are associated with abrupt decreases (increases) in the temperature value. During these days of low CI, extremely high values also occur in southern Spain. For example, Seville (see location in Fig. $3 \mathrm{~b}$ can reach temperatures near $40^{\circ} \mathrm{C}$. Thus, $\mathrm{CI}$ is able to detect stagnation not only over Madrid, but also over most of Spain. Furthermore, CI can be used as a maximum temperature indicator. To test the association between CI and lagged maximum temperatures over Madrid and Seville, the cross-correlation functions have been computed for the daily values obtained for the summer months (June to September) during the 1955-1998 period. In Madrid, it can be seen that maximum values correspond to a 1-day lag, with a Pearson coefficient value of $-0.75(p<0.01)$, as compared to the value of $r=-0.7,(p<0.01)$ for lag zero. These values indicate the excellent agreement between $\mathrm{CI}$ and maximum temperature, and that CI can anticipate the occurrence of extreme values, one day ahead in Madrid and it can be used as a local predictor of extreme temperature. In Seville, correlation values are very similar, $r=-0.72$ for lag zero and $r=-0.67$ for a 1-day lag. The small differences in the correlation values can be attributed to the fact that Seville is located southern of Madrid and closer to the sea, and is more sensitive to variations in the wind configuration.

The Pearson correlation coefficient between CI and the daily maximum temperature has been computed for the whole study period. For all the cases, the correlation is significant and shows a certain trend towards more significant values when moving towards the end of the study period. This can be attributed to the highest frequency of stagnation situations during the end of the period; the years with few or no stagnation days correspond to lower correlation coefficients. 


\section{Final remarks}

Extreme temperatures in Madrid usually occur as short duration events, with more than $45 \%$ of the events lasting from 1 to 2 days. It is interesting to note that the determination of the threshold value $\left(36.5^{\circ} \mathrm{C}\right)$ is chosen due to the impact of extreme temperature on mortality; however, it coincides with the 95 percentile of the daily maximum temperature distribution. Thus, the occurrence of a very hot day that causes a significant impact on the mortality in Madrid is a very rare event. Long heat waves, similar to those recorded in other cities (Sartor, 1995; Smoyer, 2000; Katsouyanni, 1993), have not occurred in Madrid during the period of 1955-1998. Two synoptic patterns lead to the occurrence of temperature extremes:

(a) a southern flux situation with the injection of hot and dry air from North Africa onto Iberia, and

(b) a stagnation situation produced by the combination of a surface high and an upper level ridge oriented from SW to NE.

The duration of the southern flux situation is usually shorter (1.6 days) than that of the stagnation situations (2.7 days). This difference is due to the fact that a southern flux situation is more dynamical than a stagnation situation, which is characterized by weak winds or calm air allowing for its persistence for longer periods.

The southern flux and the stagnation situations account for $92 \%$ of the total number of days with maximum temperatures above $36.5^{\circ} \mathrm{C}$. Synoptic situations, corresponding to other hot days, are characterized by anomalies in the SLP or $500 \mathrm{hPa}$ geopotential height field that drag air from North Africa onto Iberia, but there is no clear pattern associated with the generation of such southern fluxes, so that they cannot be included in any other category. They usually have a short duration ( 1 or 2 days), since, the anomaly weakens or moves, thus changing the wind pattern and the temperature of the air mass. Thus, this classification seems to be well adapted to encompass most EHD events.

The relationship between the annual frequency of these days and the different indices, such as major teleconnections or averaged annual temperatures, has been investigated, but none of them seem to exert any significant influence. Thus, local factors tied to the circulation anomalies associated to the southern edge of the Azores' high seem to be the only relevant factors that explain the occurrence of thermal extremes.

Middle troposphere circulation controls the synoptic patterns, leading to extreme temperatures over Madrid, so a circulation index, expressed as the mean value of the anomaly of the $500 \mathrm{hPa}$ geopotential height for a referencee value of $5920 \mathrm{~m}$, computed on a grid, provides a good predictor of the occurrence of EHD one day ahead.

These results provide some interesting clues on the difficulties of assessing the local impact of a possible climate change. When trying to evaluate this type of impact, the usual procedure requires the availability of:

(1) climate scenarios, usually obtained through the averaging of a number of runs from GCMs and expressed as monthly or higher scale means,

(2) a downscaling scheme to allow for the regional scale description of the variables, and

(3) a model to estimate the impact of climate change.

In our case, the impact on mortality can be directly measured and does not present any problems when accurate daily maximum temperatures are available. However, this paper shows that the frequency of EHD depends, nonlinearly, on the monthly averaged maximum temperature, but there is no significant relationship at higher time scales. Thus, only those scenarios providing maximum daily or monthly temperature (or daily $Z_{500}$, to evaluate the $\mathrm{CI}$ ) will be useful for properly assessing the temperature impact on mortality. The use of scenarios expressing temperatures or $Z_{500}$, as seasonal averages will introduce additional uncertainty in the evaluation of these local impacts, even when these parameters can be directly estimated with a simple model from the meteorological variables.

Acknowledgement. Topical Editor J.-P. Duvel thanks I. Durre and J. Coiffier for their help in evaluating this paper.

\section{References}

Alberdi, J. C., Díaz J., Montero, J. C., Mirón, I. J.: Daily mortality in Madrid Community (Spain) 1986-1991: Relationship with atmospheric variables, European Journal of Epidemiology, 14, 571-578, 1998.

Chang, F. and Wallace, J. M.: Meteorological Conditions during Heat Waves and Drounghts in the United States Great Plains, Monthly Weather Review, 115, 1253-1269, 1987.

Changnon, S., Kunkel, K., and Reinke B.: Impacts and Responses to the 1995 Heat Wave: A Call to Acction, Bulletin of the American Meteorological Society, 77, 1497-1506, 1996.

Díaz, J., García, R., Ribera, P., Alberdi, J. C., Hernández, E., and Pajares, M. S.: Modeling of air pollution and its relationship with mortality and morbidity in Madrid (Spain), International Archives Occupational and Environmental Health, 72, 366-376, 1999.

Díaz, J., López, C., García, R., Jordán, A., Hernández, E., Alberdi, J. C., and Otero, A.: Heat Waves in Madrid, 1986-1997: effects on the health of the elderly, International Archives Occupational and Environmental Health, On-line: Nov. 2001.

Easterling, D. R., Meehl, G. A., Parmesan, C., Chagnon, S. A., Karl, T. R., and Mearns, L. O.: Climate Extremes: Observations, Modeling and Impacts. Science, 289, 2068-2074, 2000.

González, S., Díaz, J., Pajares, M. S., Alberdi, J. C., Otero, A., and López, C.: Relationship between atmospheric pressure and mortality in the Madrid Autonomus Regio: a timeseris study, International Journal of Biometeorology, 45, 34-40, 2001.

Greenberg, J. H., Bromberg, J., Reed, C. M., Gustafson, T. L., and Beauchamp, R. A.: The epidemiology of heat-related deaths, 
Texas - 1950, 1970-79 and 1980. American Journal of Public Health, 73, 805-807, 1983.

IPCC: The IPCC Assessment of knowledge relevant to the interpretation of article 2 of the UN framework conention on climate change: a synthesis report, Geneva, 1995.

Kalkstein, L.: A new approach to evaluate the impact of climate on human mortality, Environmental Health Perspectives, 96, 145150, 1991.

Kalkstein, L., Nichols, M. C., Barthel, C. D., and Greene, J. S.: A new spatial synoptic classification: application to air-mass analysis, International Journal of Climatology, 16, 983-1004, 1996.

Kalkstein, L. S. and Greene, J. S.: An evluation of climate/mortality relationships in large U.S. cities and the possible impacts of a climate change, Environmental Health Perspectives, 105, 84-93, 1997.

Kalnay, E. et al.: The NCEP/NCAR 40-year reanalysis project, Bulletin of the American Meteorological Society, 77, 437-471, 1996.

Karl, T. R. and Quayle, R. G.: The 1980 summer heat wave and drought in historical perspective, Monthly Weather Review, 109, 2055-2073, 1981.

Karl, T. M, Knight, R. W., Easterling, D. R., and Quayle, R. G.: Indices of Climate Change for the United States, Bulletin of the American Meteorological Society, 77, 279, 1996.

Katsouyanni, K., Pantazopoulou, A., Touloumi, G., Tselepidaki, I., and Moustris, K., et al.: Evidence for interaction between air pollution and high temperature in the causation of excess mortality, Archives of Environmental Health, 48, 235-242, 1993.

Kunst, A. E., Looman, C. W. N., and Mackenbach, J. P.: Outdoor air temperature and mortality in the Netherlands: A time-series analysis, American Journal Epidemiology, 137, 331-341, 1993.

Lye, M. and Kamal, A.: Effects of a heatwave on mortlity-rates in elderly inpatients, Lancet, 1, 529-531, 1997.

Macey, S. M. and Schneider, D. F.: Deaths from excessive heat and excesive cold among the elderly, The Gerontologist, 33, 497500, 1993.

Nakai, S., Itoh, T., and Morimoto, T.: Deaths from heat-stroke in Japan: 1968-1994, International Journal of Biometeorology, 43, 124-127, 1999.
Pan, W. H., La, Li., and Tsai, M. J.: Temperature extremes and mortality from coronary heart disease and cerebral infarction in elderly Chinese, The Lancet, 345, 353-355, 1995.

Plummer, N., et al: Changes in climate extremes over the Australian region and New Zeland during the Twentieth century, Climate Change, 42, 183-202, 1999.

Richman, M. B.: Review article, rotation of principal components, J. Climatol., 6, 293-335, 1986.

Sáez, M., Sunyer, J., Castellsagué, J., Murillo, C., and Antó, J. M.: Relationship between weather temperture and mortality: a time series analysis approach in Barcelona, International Journal Epidemiology, 24, 576-582, 1995.

Sartor, F., Snacken, R., Demuth, C., and Walckiers, D.: Temperature, ambient ozone levels and mortality during summer 1994 in Belgium, Environmental Research, 70, 105-113, 1995.

Samet, J., Zeger, S., Kelsall, J., Xu, J., and Kalkstein, L. S.: Does weather confound or modify the association of particullate airpollution with mortality? An analysis of the Philadelphia data, 1973-1980, Environmental Research, 77, 9-19, 1998.

Smoyer, K. E.: A comparative analysis of heat waves associated mortality in St. Louis, Missouri - 1980 and 1995, International Journal of Biometeorology, 42, 44-50, 1998.

Smoyer, K. E., Rainham, D. G. C., and Hewko, J. N.: Heat-Stressrelated mortality in five cities in Southern Ontario: 1980-1996, International Journal of Biometeorology, 44, 190-197, 2000.

Ungar, S.: Is Stange Weather in the Air? A Study of U.S. National: Network News Coverage of Extreme Weather Events, Climatic Change, 41, 133-150, 1999.

Von Storch, H. and Zwiers, F. W.: Statical analzsis in climate research, Camebridge University Press, 1999.

Whitman, S., Good, G., Donoghue, E. R., Benbow, N., Shou, W., and Mou, S.: Mortality in Chicago attributed to the July 1995 Heat Wave, American Journal of Public Health, 87, 1515-1518, 1997.

Woodhouse, P. R., Khaw, K. T., Plummer, M., Foley, A., and Meade, T. W.: Seasonal variation of plasma fibrinogen and factor VII activity in the elderly: winter infections and death form cardiovascular disease, Lancet, 343, 435-439, 1994. 